\title{
Synthesis and physical properties of biodegradable nanocomposites fabricated using acrylic acid- grafted poly(butylene carbonate-co-terephthalate) and organically-modified layered zinc phenylphosphonate
}

\section{Yi-Fang Lee}

National Chung Hsing University College of Engineering

Tzong-Ming Wu ( $\nabla$ tmwu@dragon.nchu.edu.tw )

National Chung Hsing University https://orcid.org/0000-0002-0170-2595

\section{Research Article}

Keywords: biodegradable aliphatic-aromatic copolyesters, nanocomposites, thermal properties, mechanical properties

Posted Date: March 26th, 2021

DOI: https://doi.org/10.21203/rs.3.rs-331974/v1

License: (1) This work is licensed under a Creative Commons Attribution 4.0 International License. Read Full License

Version of Record: A version of this preprint was published at Journal of Polymers and the Environment on July 24th, 2021. See the published version at https://doi.org/10.1007/s10924-021-02245-9. 


\section{Abstract}

A set of novel biocompatible aliphatic-aromatic nanocomposites, including numerous acrylic acid-grafted poly(butylene carbonate-co-terephthalate) (g-PBCT) and organically-modified layered zinc phenylphosphonate (m-PPZn), were successfully synthesized via polycondensation and transesterification. A primary covalent linkage was produced between the biocompatible polymer and the inorganic reinforcements. Fourier transform infrared spectroscopy and ${ }^{13} \mathrm{C}$-nuclear magnetic resonance spectra demonstrated the successful grafting of acrylic acid into the PBCT (g-PBCT). Both wide-angle Xray diffraction data and X-ray photoelectron spectroscopy analysis showed that the g-PBCT polymer matrix was intercalated into the interlayer spacing of the m-PPZn and was chemically interacted with the $m-P P Z n$. The addition of $m-P P Z n$ in the g-PBCT matrix significantly improved its storage modulus. A slight increase in thermal stability was observed in all the g-PBCT/m-PPZn composites. Both results are attributed to the presence of covalent bond between g-PBCT and m-PPZn.

\section{Introduction}

Biodegradable polymers, such as poly(lactic acid) (PLA) and poly(1,4-butanediol succinate) (PBS), have been commercially utilized to resolve the existing problem of plastic waste accumulation. However, the commercial applications of these aliphatic biodegradable polymers are limited owing to their relatively poor physical properties and high costs [1]. In order to improve the physical properties and reduce the cost of aliphatic biodegradable polyesters, Witt et al. reported an investigation to be copolymerized the aliphatic biodegradable polyesters with aromatic polyesters because aromatic polyesters have excellent mechanical properties [2]. The fabricated aliphatic-aromatic poly(butylene adipate-co-terephthalate) (PBAT) copolyester is biodegradable, while the content of the aromatic units is up to $60 \mathrm{~mol} \%$. The PBAT are extremely resistant to microbial attack and can be produced at low cost $[3,4]$.

Compared with aliphatic polyesters, aliphatic polycarbonates are more feasible candidates for biomedical applications owing to the absence of acidic compounds during its in vivo degradation [5]. Jung et al., conducted condensation copolymerizations of dimethyl carbonate (DMC), dimethyl terephthalate (DMT), and 1,4-butanediol (BD) via a two-step process using sodium alkoxide as a catalyst with a varying [DMT]/[DMC] feed ratio to form poly(butylene carbonate-co-terephthalate) (PBCT) [6]. The prepared PBCTs consisting of $40-50 \mathrm{~mol} \%$ aromatic terephthalate units demonstrated thermal properties comparable to commercial compostable aliphatic polyesters such as PLA, PBS, and poly(butylene succinate-co-adipate) (PBSA). Melting temperatures of the PBCT were observed to be in the range of 95$146^{\circ} \mathrm{C}$, which could be varied by the content of terephthalate unit with a fast crystallization rate.

Recently, a two-dimensional layered zinc phenylphosphonate (PPZn), a character of synthetic organic/inorganic hybrid material with a layered structure that is analogous to montmorillonite (MMT), has attracted a lot of attention owing to their potential application in adsorption topic, catalysis, and polymer composites [7, 8]. Alkylamines can be effectively intercalated into the interlayer spacing of PPZn. The interlayer spacing of organically-modified PPZn can be extensively improved and the extent of this 
enhancement is a function of the chain length of the alkylamines. A large interlayer distance of organically-modified PPZn could act as a reinforcement for polymer nanocomposites to significantly enhance the crystallization rates and physical properties of polymers $[9,10]$. In our previous study, two biocompatible long-chain primary alkylamines, such as dodecylamine and octadecylamine, were applied to produce the organically-modified PPZn (o-PPZn) through anion exchange method [11]. A series of new biodegradable poly(butylene carbonate-co-terephthalate)/o-PPZn nanocomposites containing various weight ratios of o-PPZn were first reported and successfully synthesized. The physical properties and enzymatic degradation of nanocomposites were investigated. From this investigation, the interaction between polymer and reinforcing material is noncovalent bond. Generally, covalent linkages between polymer and reinforcing material are more useful and stable than noncovalent bonds. Another approach with chemically grafted technique had been applied to enhance the physical properties of polymers. Wu et al. reported the effects of replacing PCL with acrylic acid-grafted PCL (PCL-g-AA) on the structure and properties of a PCL/chitosan blend. The presence of PCL-g-AA in the blend facilitates its compatibility with chitosan, consequently, there is a significant improvement in the properties of the blend due to the formation of ester and imide groups which enhances the dispersion and homogeneity of chitosan in the matrix [12].

In this study, a set of novel biodegradable composites, including numerous acrylic acid-grafted poly(butylene carbonate-co-terephthalate) (g-PBCT) and organically-modified layered PPZn, were successfully synthesized via polycondensation and transesterification. Organo-modifiers with at least two functional groups are necessary to provide the possible formation of covalent bonding between PPZn and acrylic acid-grafted PBCT. The biocompatible and nontoxic 1,12-diaminododecan with two amino groups was used to manufacture the organically-modified PPZn (m-PPZn) via a co-precipitation method. From our detailed research, no study on g-PBCT/m-PPZn nanocomposites with covalent linkages between the g-PBCT and $\mathrm{m}-\mathrm{PPZn}$ has been reported, thus, this is novel research. The mechanical and thermal properties of $\mathrm{g}$-PBCT/m-PPZn nanocomposites were systematically studied.

\section{Experimental}

\section{Materials}

Zinc nitrate hexahydrate, 1,12-diaminododecan, dimethyl carbonate (DMC), 1,4-butanediol (BD), dimethyl terephthalate (DMT) were acquired from Alfa Aesar Chemical Company. 1-ethyl-3-(3dimethylaminopropyl)carbodiimide (EDC), sodium hydroxide $(\mathrm{NaOH})$ were got from Sigma-Aldrich Chemical Company. Phenylphosphonic acid was obtained from Acros Organics Chemical Company. Acrylic acid (AA) was gained from Tedia Company, Inc. 2,2'-Azobis-isobutyronitrile (AIBN) was received from Showa Chemical Industry Co., Ltd. All chemicals were used without purification.

\section{Fabrication of g-PBCT/m-PPZn nanocomposites}

Three different molar ratios of PBCT were synthesized via polycondensation and transesterification, which has been previously investigated $[5,6,13-17]$. The feed molar ratios of [DMC] to [DMT] were 90:10, 
50:50, and 30:70 and assigned amounts of BD; the fabricating products are hereinafter designated as PBCT-90, PBCT-50, and PBCT-30, respectively. In brief, the BD, DMC, DMT, and $\mathrm{NaOH}$ as a catalyst were added to the four-necked flask under $\mathrm{N}_{2}$ gas, which was heated at $120^{\circ} \mathrm{C}$ for $1 \mathrm{~h}$. The pressure was reduced to $570 \mathrm{mmHg}$ and the heating temperature was increased to $190^{\circ} \mathrm{C}$ for 5 mins; The pressure was then further reduced to $380 \mathrm{mmHg}$, and condensation was conducted for $5 \mathrm{mins}$ at $190^{\circ} \mathrm{C}$. The pressure was then further reduced to $190 \mathrm{mmHg}$, and the condensation reaction was conducted for another $2 \mathrm{~h}$. Finally, the polycondensation was conducted for $8 \mathrm{~h}$ at $210^{\circ} \mathrm{C}$ under full evacuation at $0.3 \mathrm{mmHg}$. The as-fabricated PBCT was dissolved in dichloromethane, and then precipitated from cold methanol for purification.

The chemical modification of PBCT and PPZn and the preparation of the resultant composites are presented in Figure 1. The synthesized PBCT was dissolved in chloroform and a mixture of AIBN and AA were added to the prepared solution at $60^{\circ} \mathrm{C}$ for $24 \mathrm{~h}$ to allow the grafting reaction to happen (hereafter designated as g-PBCT). The PPZn and 1,12-diaminododecan-modified PPZn (m-PPZn) were synthesized using the approaches reported previously $[12,13]$. Various amounts of $g-P B C T, m-P P Z n$ and EDC as a catalyst for the chemical interaction between the biodegradable polymer and the reinforcing materials were separately dissolved in dichloromethane, and then stirred for 3 days. The fabricated g-PBCT/mPPZn nanocomposites were dried in vacuum. The nanocomposites are identified as $\mathrm{xwt} \% \mathrm{~g}-\mathrm{PBCT} / \mathrm{m}$ PPZn, where $x w t \%$ is the weight percent of $m-P P Z n$.

\section{Methods}

The measurements of wide-angle X-ray diffraction (WAXD) were performed using an X-ray diffractometer (Bruker D8) equipped with a Ni-filtered $\mathrm{Cu}$ Ka radiation source. The diffraction patterns were obtained in the range of $2 \theta=1.5^{\circ}-30^{\circ}$ at a scanning rate of $1^{\circ} / \mathrm{min}$. Fourier transform infrared (FTIR) experiments were performed in the range of 400 to $4000 \mathrm{~cm}^{-1}$ on a Perkin-Elmer Spectrum One spectrometer.

The crystalline melting temperature $\left(T_{m}\right)$ for the g-PBCT/m-PPZn nanocomposites was operated using a PerkinElmer Pyris Diamond DSC. All specimens were heated to the designed temperatures $\left(T_{d s}\right)$ at a rate of $10^{\circ} \mathrm{C} / \mathrm{min}$ under nitrogen environment, which are about $50^{\circ} \mathrm{C}$ higher than the $\mathrm{T}_{\mathrm{m}}$ of $\mathrm{g}$-PBCT and held for $5 \mathrm{~min}$ to eliminate the residual crystals. Subsequently, they were cooled to $-50{ }^{\circ} \mathrm{C}$ at a rate of 10 ${ }^{\circ} \mathrm{C} / \mathrm{min}$. Finally, the samples were heated to $T_{d s}$ at a rate of $10{ }^{\circ} \mathrm{C} / \mathrm{min}$ and the $T_{m}$ for the g-PBCT and g$\mathrm{PBCT} / \mathrm{m}$-PPZn nanocomposites are obtained. The thermal behaviors of specimens were performed using Perkin Elmer TG/DTA 6300 thermoanalyzer. These measurements were obtained from room temperature to $800^{\circ} \mathrm{C}$ at a heating rate of $10^{\circ} \mathrm{C} / \mathrm{min}$ under an air environment.

${ }^{1} \mathrm{H}$-nuclear magnetic resonance (NMR) and ${ }^{13} \mathrm{C}-\mathrm{NMR}$ spectra was measured using Agilet Technologies DD2 $600 \mathrm{MHz}$ NMR spectrometer via $\mathrm{CDCl}_{3}$ as solvent and internal standard. X-ray photoelectron spectroscopy (XPS) analysis was obtained on a PHI 5000 Versa Probe X-ray photoelectron spectrometer with the incident radiation consisting of $\mathrm{Mg} \mathrm{K}_{\mathrm{a}} \mathrm{X}$-ray and the takeoff angle fixed at $45^{\circ}$. The gel permeation chromatography (GPC; Waters 717 Plusautosampler, Waters Instruments, Rochester, NY, USA) 
was used to confirm the weight-average molecular weight $\left(M_{\mathrm{w}}\right)$, number-average molecular weight $\left(M_{\mathrm{n}}\right)$, and polydispersity PDI $=M_{\mathrm{w}} / M_{\mathrm{n}}$ of the resulting polymers and composite materials. The narrow molecular-weight distributions of polystyrene standards were utilized as calibration. The storage modulus $\left(E^{\prime}\right)$ was carried out on a Perkin Elmer dynamic mechanical analyzer (DMA) from -80 to $120^{\circ} \mathrm{C}$ at 3 ${ }^{\circ} \mathrm{C} /$ min heating rate and $1 \mathrm{~Hz}$ constant frequency.

\section{Results And Discussion}

\section{Synthesis and structure of the various g-PBCT/m-PPZn nanocomposites}

The various compositions of PBCT copolyesters were clarified via ${ }^{1} \mathrm{H}-\mathrm{NMR}$ spectroscopy. Figure 2 reveals the ${ }^{1} \mathrm{H}-\mathrm{NMR}$ data of the PBCT-50 copolymers. The signal of phenylene $\left(-\mathrm{C}_{6} \mathrm{H}_{4}-\right)$ was obtained at $8.1 \mathrm{ppm}$ as a singlet while the signals of $-\mathrm{CH}_{2} \mathrm{O}$ - and $-\mathrm{CH}_{2} \mathrm{CH}_{2} \mathrm{O}$ - groups were obtained within 4.5-4.1 and 2.1-1.7 ppm, respectively. The $-\mathrm{CH}_{2} \mathrm{O}$ - signal was divided into two signals at 4.5-4.3 and 4.3-4.1 ppm; the former is designated to $-\mathrm{CH}_{2} \mathrm{O}(\mathrm{CO}) \mathrm{C}_{6} \mathrm{H}_{4}$ ( (ester) and the latter to $-\mathrm{CH}_{2} \mathrm{O}(\mathrm{CO}) \mathrm{O}$ - (carbonate). The calculated peak areas of these two signals allowed the determination of the mole fraction of the terephthalate units; $F[T P A]=\left(A_{4.5-4.3}\right) /\left(A_{4.5-4.3}+A_{4.3-4.1}\right)$ where $A$ is the calculated peak area signified by the subscript $[5,6]$. Table 1 shows the chemical composition of PBCT-50 copolyester determined using F[TPA]. The molar ratio of carbonate to terephthalate is very close to the feed ratio of [DMC] to [DMT], recommending that the composition of the fabricated $\mathrm{PBCT}$ is approximately equal to the calculated composition on the basis of the feed ratio.

Related results for the synthesized PBCT copolymers with various [DMC]/[DMT] compositions are also given in Table 1. The molecular weights of the numerous PBCT copolymers clarified using GPC are also recorded in Table 1. The weight-average molecular weight $\left(M_{w}\right)$ and polydisperse indices (PDI) of the fabricated PBCT copolymers were in the range of $26600-35300 \mathrm{~g} / \mathrm{mol}$ and $1.70-1.77$, respectively. The glass-transition temperatures and the melting temperatures of the numerous PBCT copolymers verified via DSC are also listed in Table 1. The melting temperatures of PBCT-30, PBCT-50, and PBCT-90 are 180.4, 155.4 , and $42.4^{\circ} \mathrm{C}$, respectively.

Figure 3 displays the FTIR spectra of PBCT-50 and g-PBCT-50. The absorption peaks of PBCT-50 and gPBCT-50 around 1102 and $1233 \mathrm{~cm}^{-1}$ are assigned to the stretching of the -COC- bonds in the ester group $[18,19]$. The characteristic absorption peaks at 1027 and $1729 \mathrm{~cm}^{-1}$ are attributed to the stretching vibration of the $\mathrm{O}-\mathrm{C}-\mathrm{C}$ bonds in the polymer backbone and the $-\mathrm{C}=0$ bonds of the carbonyl group, respectively [20]. An additional peak at about $1716 \mathrm{~cm}^{-1}$ corresponded to the $\mathrm{O}-\mathrm{C}=\mathrm{O}$ bond was observed in the modified polymer, which reveals the existence of free acid in the modified PBCT. This result reveals the acrylic acid group is successfully grafted onto PBCT. Similar results have been reported in previous literature [21, 22]. Analysis of the ${ }^{13} \mathrm{C}$-NMR spectra presents additional support for the successful grafting of $A A$ as presented in Figure 4. The ${ }^{13} \mathrm{C}-\mathrm{NMR}$ spectra of g-PBCT-50 contain an additional small peak at $\delta$ 
$=173.3 \mathrm{ppm}$ relative to that of ungrafted $\mathrm{PBCT}-50$. This peak is attributed to the $\mathrm{O}-\mathrm{C}=0$ bond of the $\mathrm{AA}$, which also confirms the grafting of AA into PBCT [20,21].

The WAXD diffraction profiles of different compositions of g-PBCT copolyesters were represented in Figure 5. Five strong diffraction peaks at $2 \theta=16.1^{\circ}, 17.4^{\circ}, 20.7^{\circ}, 23.3^{\circ}$, and $25.2^{\circ}$ were obtained for the gPBCT-30 and g-PBCT-50 specimens, which indicate the crystalline form of polybutylene terephthalate (PBT) $[6,19]$. These results demonstrated that the crystal structure of g-PBCT-30 and g-PBCT-50 are dominated by the crystalline PBT. As presented in this figure, the diffraction peaks of the g-PBCT-90 copolymers at $2 \theta=21.2^{\circ}$ and $21.7^{\circ}$ are comparable with those of crystalline polybutylene carbonate (PBC) [6]. This finding discloses that the structure of the fabricated g-PBCT-90 copolymer was transformed from the crystal structure of PBT to the crystal structure of PBC. As presented in Table 2, the melting temperatures of g-PBCT-3, g-PBCT-50, and g-PBCT-90 determined by DSC were 177.6, 159.2, and $41.4^{\circ} \mathrm{C}$, respectively.

Figure 6 exhibits the XPS data of the g-PBCT-50 copolyester and g-PBCT/m-PPZn nanocomposite. XPS analysis is an effective instrument that was used to illustrate the formation of amide linkages in the $\mathrm{g}$ PBCT-50/m-PPZn nanocomposites. It is evident from Figure 6 that an extra peak of nitrogen at the binding energy of $400 \mathrm{eV}$ was observed for the g-PBCT/m-PPZn nanocomposite [22]. This result recommends that the structural change from the $\mathrm{O}-\mathrm{C}=\mathrm{O}$ formation of $\mathrm{g}-\mathrm{PBCT}-50$ to $\mathrm{N}-\mathrm{C}=\mathrm{O}$ formation of $\mathrm{g}$ PBCT-50/m-PPZn nanocomposites.

Figure 7 shows the WAXD diffraction curves of the g-PBCT-50/m-PPZn nanocomposites. For comparison, the X-ray diffraction data of $\mathrm{m}-\mathrm{PPZn}$ is also shown in this figure. $\mathrm{A}$ small trace of diffraction peak at $2 \theta=$ $5.9^{\circ}$ was clearly observed in the experimental results of the specimens of high m-PPZn content, which contributes to the stacking layers of m-PPZn. These findings indicate that the intercalated conformation was obtained for the g-PBCT-50/m-PPZn nanocomposites. Similar findings were also observed for the gPBCT-30/m-PPZn and g-PBCT-90/m-PPZn nanocomposites.

\section{Physical properties of the various $\mathrm{g}-\mathrm{PBCT} / \mathrm{m}-\mathrm{PPZn}$ nanocomposites}

TGA analysis was operated to investigate the thermal behaviors of the various $\mathrm{g}-\mathrm{PBCT} / \mathrm{m}-\mathrm{PPZn}$ nanocomposites. Figure 8 presents the TGA curves of the g-PBCT-50/m-PPZn nanocomposites. Similar findings were also observed for the g-PBCT-30/m-PPZn and g-PBCT-90/m-PPZn nanocomposites. The slight increase in the initial degradation temperature and the temperature of maximum degradation rate illustrated in these patterns is recorded in Table 2. As presented in this table, the temperature of maximum degradation rate for the g-PBCT-30 and g-PBCT-50 is higher than that of g-PBCT-90. These experimental observations reveal that the thermal stability of g-PBCT-90 is relative lower as compared to these synthesized copolyesters, analogous to previously reported results of PBCT copolymers without grafting reaction [5]. Nevertheless, the slight increase in the temperature of maximum degradation rate of the g-PBCT/m-PPZn nanocomposites is higher compared to those of the g-PBCT copolymers. This finding is assigned to the presence of $\mathrm{m}$-PPZn in the g-PBCT matrix, which can cause the covalent bond between $\mathrm{g}$-PBCT and m-PPZn, thus, increasing the thermal stability. 
The change of storage modulus $(E)$ against temperature of g-PBCT-50/m-PPZn nanocomposites in a temperature ranging from -70 to $80^{\circ} \mathrm{C}$ is presented in Figure 9 . The $E^{\prime}$ of g-PBCT-50 at $-70{ }^{\circ} \mathrm{C}$ is around $1570 \mathrm{MPa}$ and decreases as the temperature increases. This result reveals that the molecular motion of $\mathrm{g}$-PBCT in the glassy state is not enough for a molecular transition. While the temperature is larger than the glass-transition temperature, the thermal energy ends up to be equivalent to the potential energy barriers of the molecular motions. The $E^{\prime}$ of the g-PBCT-50/m-PPZn nanocomposites at $-70{ }^{\circ} \mathrm{C}$ increases as the content of m-PPZn increases. The $E^{\prime}$ values of the g-PBCT-50/m-PPZn nanocomposites were about 1710,1930 and $2080 \mathrm{MPa}$ for 1,3 , and $5 \mathrm{wt} \%$ intercalation of m-PPZn into the g-PBCT-50 polymer matrix, respectively. The improvement of $E^{\prime}$ may be ascribed to the addition of inorganic and stiff $\mathrm{m}$-PPZn which results in covalent linkages with the g-PBCT and induces a reinforcement effect, thus, enhancing the rigidity of the g-PBCT polymer matrix. Similar results were also found for the g-PBCT-30/m-PPZn and gPBCT-90/m-PPZn nanocomposites. Detailed $E^{\prime}$ values for all the nanocomposites are also presented in Table 2 .

\section{Conclusions}

Novel biocompatible g-PBCT/m-PPZn nanocomposites were manufactured via polycondensation and transesterification. FTIR and ${ }^{13} \mathrm{C}$-NMR spectra suggest the successful grafting of AA into PBCT. Experimental results of WAXD and XPS revealed that the intercalated conformation was successful for the g-PBCT/m-PPZn nanocomposites. It was observed that the E' of g-PBCT-50 is insignificantly enhanced by the addition of $\mathrm{m}-\mathrm{PPZn}$ in the g-PBCT matrix A slight increase in thermal stability was observed in all the g-PBCT/m-PPZn composites. Both results are attributed to the presence of covalent bond between $\mathrm{g}-\mathrm{PBCT}$ and $\mathrm{m}-\mathrm{PPZn}$.

\section{Declarations}

\section{Acknowledgements}

The financial support of this work is provided by the Ministry of Science and Technology (MOST) under Grand MOST 107-2212-E-005-020 and the Ministry of Education under the project of Innovation and Development Center of Sustainable Agriculture (IDCSA).

\section{Conflicts of Interest}

The authors declare no conflict of interest.

\section{References}

1. Bordes P, Pollet E, Averous L (2009) Nano-biocomposites: Biodegradable polyester/nanoclay systems. Prog Polym Sci 34:125 
2. Witt U, Yamamoto M, Seeliger U, Müller RJ, Warzelhan V (1999) Biodegradable polymeric materialsnot the origin but the chemical structure determines biodegradability. Angew Chem Int Ed 38:1438

3. Gan Z, Kuwabara K, M. Yamamoto M, Abe H, Doi Y (2004) Solid-state structures and thermal properties of aliphatic-aromatic poly(butylene adipate-co-butylene terephthalate) copolyesters. Polym Degrade Stab 83:289

4. Shi XQ, Ito H, Kikutani T (2005) Characterization on mixed-crystal structure and properties of poly (butylene adipate-co-terephthalate) biodegradable fibers. Polymer 46:11442

5. Zhang J, Zhu W, Li C, Zhang D, Xiao Y, Guan G, Zheng L (2015) Aliphatic-aromatic poly(butylene carbonate-co-terephthalate) random copolymers: Synthesis, cocrystallization, and compositiondependent properties. J Appl Polym Sci 41952

6. Lee JJ, Jeon JY, Park JH, Jang Y, Hwang EY, Lee BY (2013) Preparation of high-molecular-weight poly(1,4-butylene carbonate-co-terephthalate) and its thermal properties. RSC Adv 3:25823

7. Poojary DM, Clearfield A (1995) Coordinative intercalation of alkylamines into layered zinc phenylphosphonate. Crystal structures from X-ray powder diffraction data. J Am Chem Soc $117: 11278$

8. Zhang Y, Scott KJ, Clearfield A (1995) Intercalation of alkylamines into dehydrated and hydrated phenylphosphonates. J Mater Chem 5:315

9. Chen YA, Chen EC, T.M. Wu TM (2015) Organically modified layered zinc phenylphosphonate reinforced stereocomplex-type poly(lactic acid) nanocomposites with highly enhanced mechanical properties and degradability. J Mater Sci 50:7770

10. Wang HT, Chen EC, Wu TM (2020) Crystallization and enzymatic degradation of maleic acid-grafted poly (butylene adipate-co-terephthalate)/organically modified layered zinc phenylphosphonate nanocomposites. J Polym Enviro 28:834

11. Tseng LY, Chen EC, Wang JM, Wu TM (2020) Synthesis, physical properties and enzymatic degradation of biodegradable nanocomposites fabricated using poly(butylene carbonate-coterephthalate) and organically modified layered zinc phenylphosphonate. Polymers 12:2149

12. Wu CS (2005) A comparison of the structure, thermal properties, and biodegradability of polycaprolactone/chitosan and acrylic acid grafted polycaprolactone/chitosan. Polymer 46:147

13. Park SY, Chun J, Jeon JY, Lee PC, Hwang Y, Song BG, Ramos R, Ryu CY, Lee BY (2015) Branched poly(1,4-butylene carbonate-co-terephthalate)s: LDPE-like semicrystalline thermoplastics. J Polym Sci A: Polym Chem 53:914

14. Ki HC, Park $O O$ (2001) Synthesis, characterization and biodegradability of the biodegradable aliphatic-aromatic random copolyesters. Polymer 42:1849

15. Park GH, Lee S, Park SH, Eo SC, Kim JG, Lee BY (2016) Chopping high-molecular weight poly(1,4butylene carbonate-co-aromatic ester)s for macropolyol synthesis. J Appl Polym Sci 43754

16. Kim JG, Jeon JY, Chun J, Kim CS, Lee PC, Lee BY (2017) Efficient synthesis of organic carbonates and poly(1,4-butylene carbonate-co-terephthalate)s. J Appl Polym Sci 44951 
17. Hsu MC, Wang JM, Wu TM (2021) Synthesis, mechanical properties and enzymatic degradation of biodegradable poly(butylene carbonate-co-terephthalate)/organically modified layered double hydroxide J Polym Environ 29:755

18. Murase SK, Aymat M, Calvet A, del Valle LJ, Puiggali J (2015) Electrosprayed poly(butylene succinate) microspheres loaded with indole derivatives: a system with anticancer activity. Euro Polym J 71:196

19. Wang HT, Wang JM, Wu TM (2019) Synthesis and characterization of biodegradable aliphaticaromatic nanocomposites fabricated using maleic acid-grafted poly(butylene adipate-coterephthalate) and organically modified layered zinc phenylphosphonate. Polym Intern 68:1531

20. Wu CS (2011) Process, characterization and biodegradability of aliphatic aromatic polyester/sisal fiber composites. J Polym Environ 19:706

21. Wu CS (2009) Antibacterial and static dissipating composites of poly(butylene adipate-coterephthalate) and multi-walled carbon nanotubes. Carbon 47:3091

22. Lin SH, Wang JM, Wang HT, Wu TM (2019) Synthesis, mechanical properties and biodegradation of various acrylic acid-grafted poly(butylene succinate-co-terephthalate)/organically modified layered zinc phenylphosphonate nanocomposites. Euro Polym J 116:1

\section{Tables}

Table 1. Composition and molecular weight of synthesized polyesters.

\begin{tabular}{|c|c|c|c|c|c|c|c|}
\hline Polymer & $\begin{array}{l}\text { Feed Ratio } \\
{[\mathrm{DMC}] /[\mathrm{DMT}]} \\
(\mathrm{mol} \%)\end{array}$ & $\begin{array}{l}\text { Polymer Ratio } \\
\text { [DMC]/[DMT] } \\
(\mathrm{mol} \%)\end{array}$ & $\begin{array}{l}M_{W} \\
(\mathrm{~g} / \mathrm{mol}) \\
\times 10^{4}\end{array}$ & $\begin{array}{l}M_{n} \\
(\mathrm{~g} / \mathrm{mol}) \\
\times 10^{4}\end{array}$ & PDI & $\begin{array}{l}\mathrm{T}_{\mathrm{g}} \\
\left({ }^{\mathrm{O}} \mathrm{C}\right)\end{array}$ & $\begin{array}{l}\mathrm{T}_{\mathrm{m}} \\
\left({ }^{\circ} \mathrm{C}\right)\end{array}$ \\
\hline PBCT-30 & $30 / 70$ & $30.0 \otimes 70.0$ & 2.66 & 1.56 & 1.70 & 21.46 & 180.4 \\
\hline PBCT-50 & $50 / 50$ & $46.8 \rrbracket 53.2$ & 3.53 & 2.04 & 1.73 & 15.84 & 155.4 \\
\hline РВCT-90 & $90 / 10$ & $88.3 \rrbracket 11.7$ & 2.69 & 1.52 & 1.77 & -14.93 & 42.4 \\
\hline
\end{tabular}

${ }^{\mathrm{a} C}$ Composition measured by ${ }^{1} \mathrm{H}-\mathrm{NMR}$.

Table 2. Initial degradation temperature, temperature of the maximum degradation rate, storage modulus at $-70{ }^{\circ} \mathrm{C}$ and melting temperatures of the various g-PBCT/m-PPZn nanocomposites. 


\begin{tabular}{|lllll|}
\hline sample & ${ }^{\mathrm{a}} T_{d}{ }^{j}$ & ${ }^{\mathrm{b}} T_{d} \max$ & $E^{\prime}$ & $\mathrm{Tm}$ \\
& $\left({ }^{\circ} \mathrm{C}\right)$ & $\left({ }^{\circ} \mathrm{C}\right)$ & $(\mathrm{GPa})$ & $\left({ }^{\circ} \mathrm{C}\right)$ \\
\hline g-PBCT-30 & 288.9 & 335.6 & $1.33 \pm 0.07$ & 177.6 \\
\hline 1wt\% g-PBCT-30/m-PPZn & 278.9 & 337.3 & $1.41 \pm 0.23$ & 179.6 \\
\hline 3wt\% g-PBCT-30/m-PPZn & 304.2 & 337.3 & $1.49 \pm 0.06$ & 180.1 \\
\hline 5wt\% g-PBCT-30/m-PPZn & 302.0 & 339.2 & $1.63 \pm 0.04$ & 180.1 \\
\hline g-PBCT-50 & 314.9 & 334.4 & $1.57 \pm 0.10$ & 159.2 \\
\hline 1wt\% g-PBCT-50/m-PPZn & 317.1 & 335.3 & $1.71 \pm 0.11$ & 159.2 \\
\hline 3wt\% g-PBCT-50/m-PPZn & 317.0 & 336.1 & $1.93 \pm 0.12$ & 159.2 \\
\hline 5wt\% g-PBCT-50/m-PPZn & 319.2 & 338.6 & $2.08 \pm 0.23$ & 159.6 \\
\hline g-PBCT-90 & 283.4 & 293.7 & $1.15 \pm 0.04$ & 41.4 \\
\hline 1wt\% g-PBCT-90/m-PPZn & 282.0 & 294.4 & $1.66 \pm 0.10$ & 41.4 \\
\hline 3wt\% g-PBCT-90/m-PPZn & 286.3 & 295.2 & $1.79 \pm 0.03$ & 41.4 \\
\hline 5wt\% g-PBCT-90/m-PPZn & 286.5 & 295.5 & $2.00 \pm 0.04$ & 41.4 \\
\hline
\end{tabular}

${ }^{\mathrm{a}} T_{d}{ }^{j}$ : Initial degradation temperature

${ }^{\mathrm{b}} T_{d}{ }^{\text {max }}$. Temperature of the maximum degradation rate

Figures 


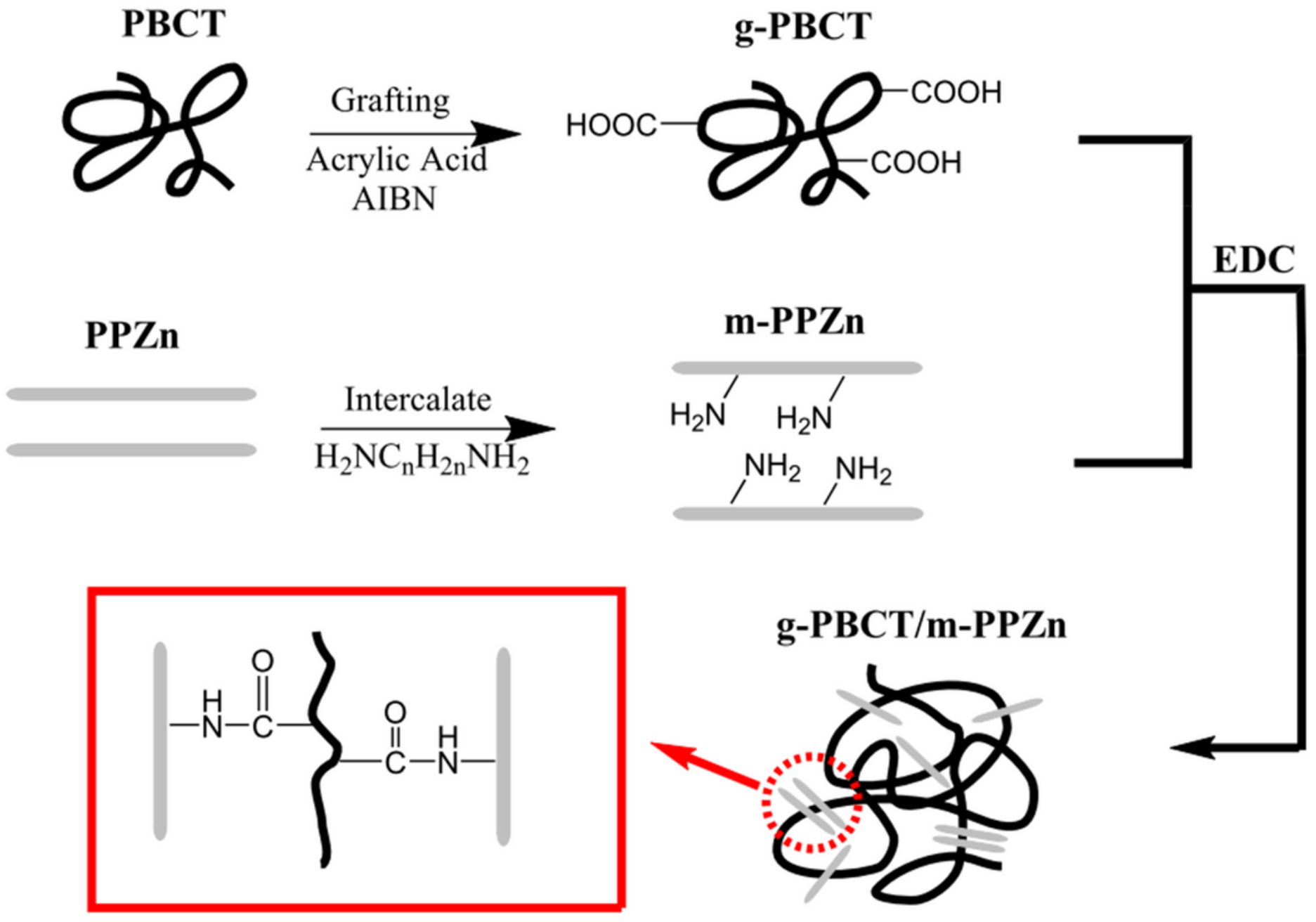

Figure 1

Reaction scheme for the modification of PBCT and m-PPZn and the fabrication of composite materials. 


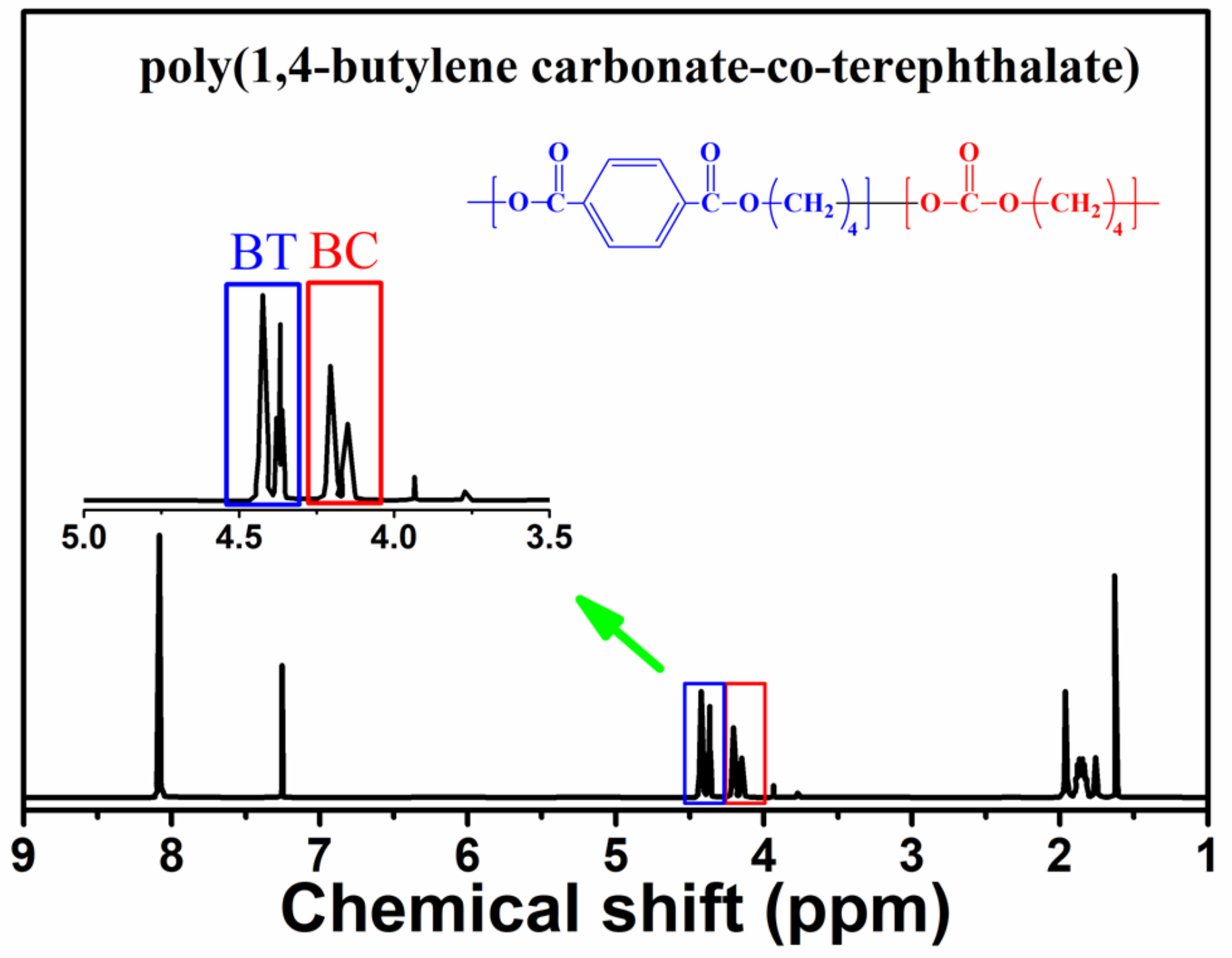

Figure 2

$1 \mathrm{H}-\mathrm{NMR}$ spectrum of the PBCT-50 copolyester. 


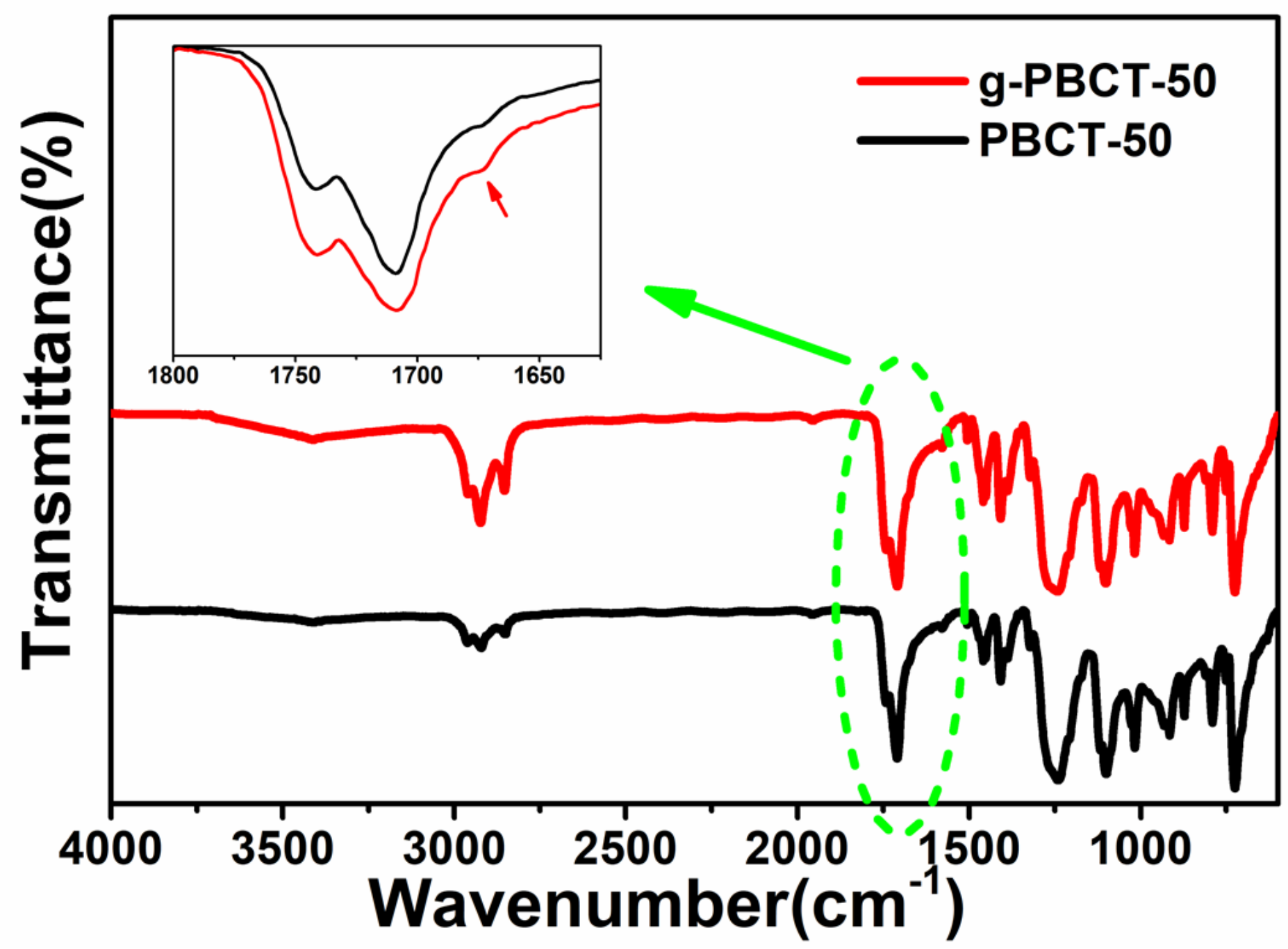

Figure 3

FTIR spectra of the PBCT-50 and g-PBCT-50 copolyesters. 


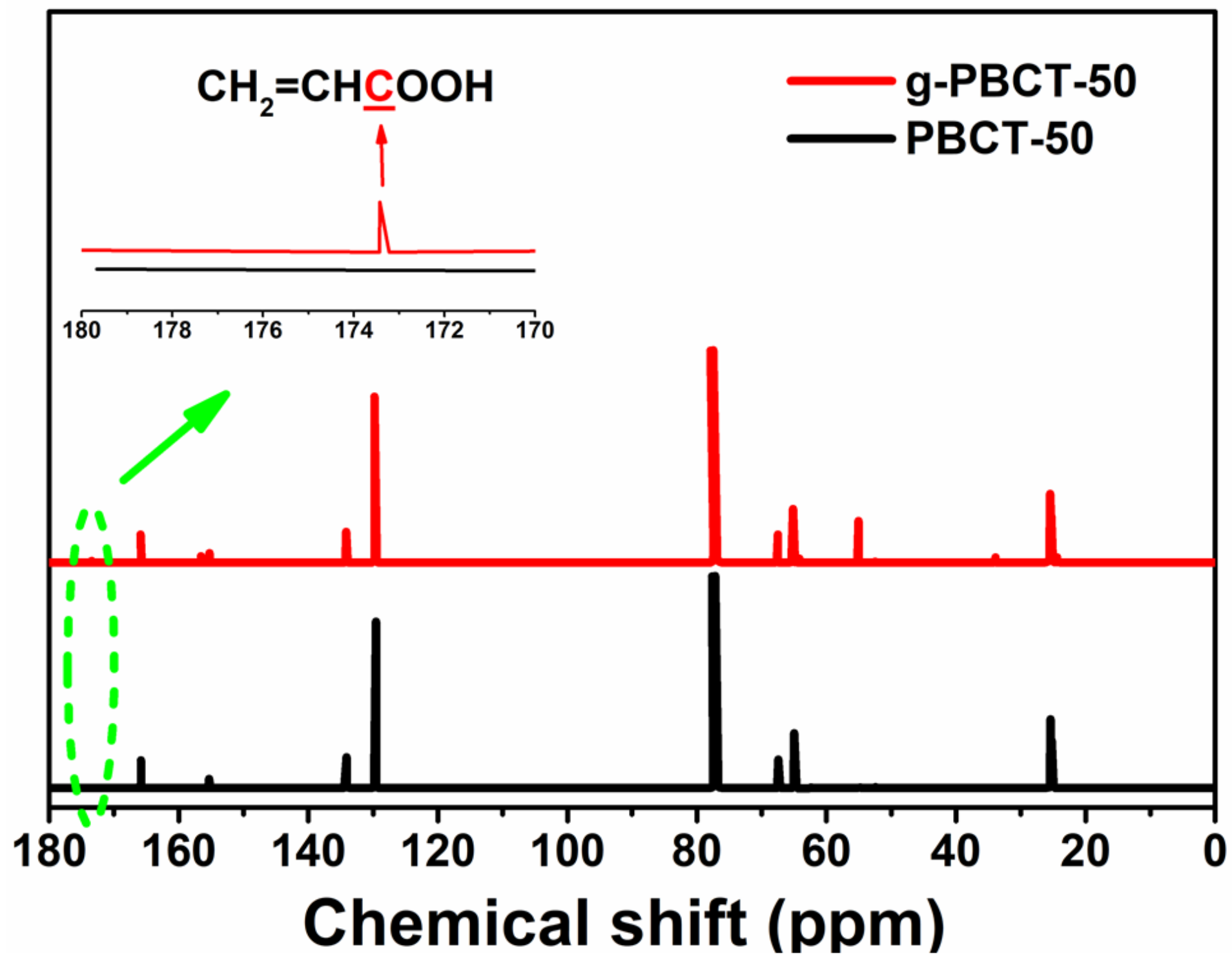

Figure 4

13C-NMR spectra of the PBCT-50 and g-PBCT-50 copolyesters. 


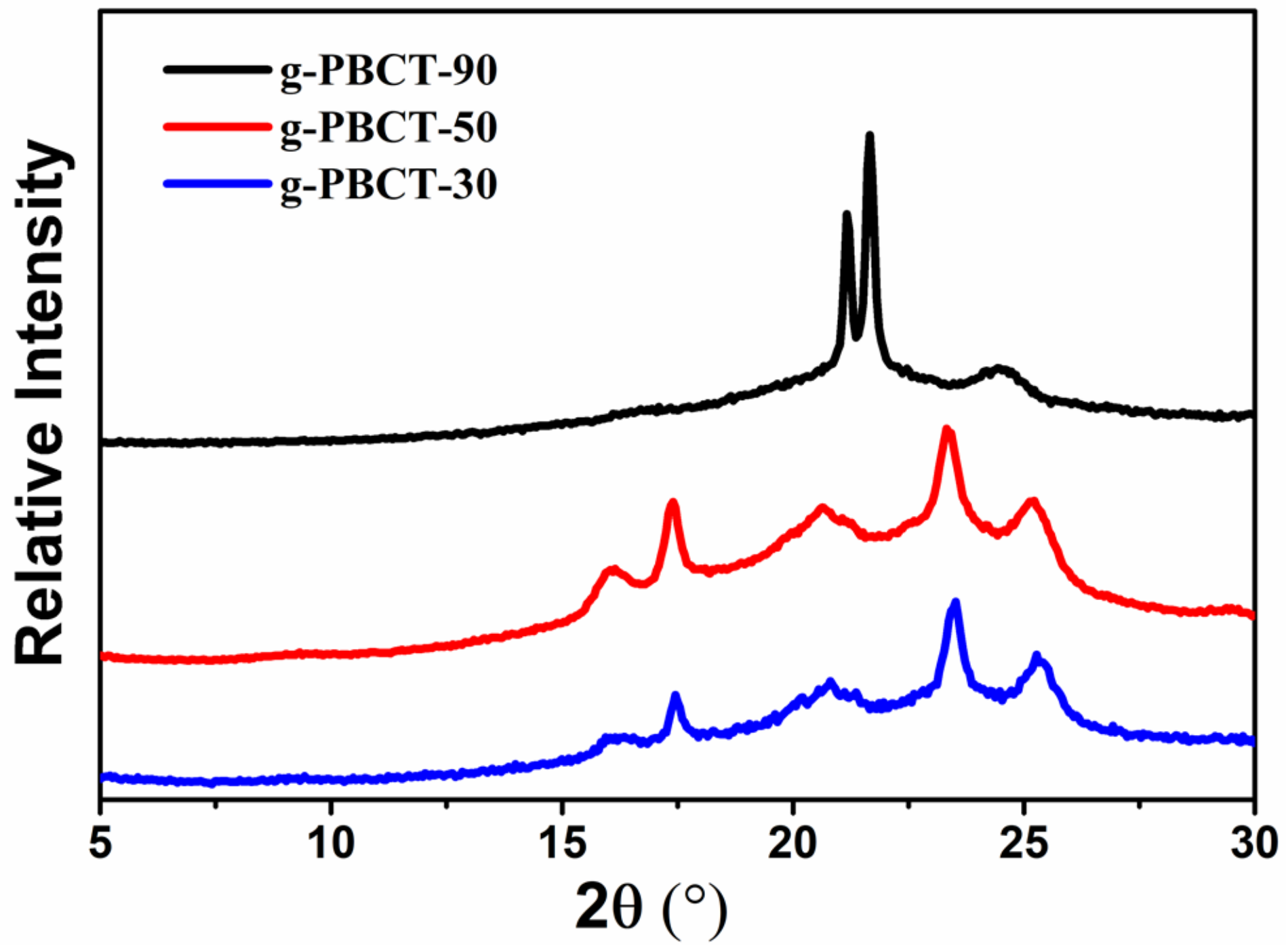

Figure 5

WAXD patterns of g-PBCT copolymers. 


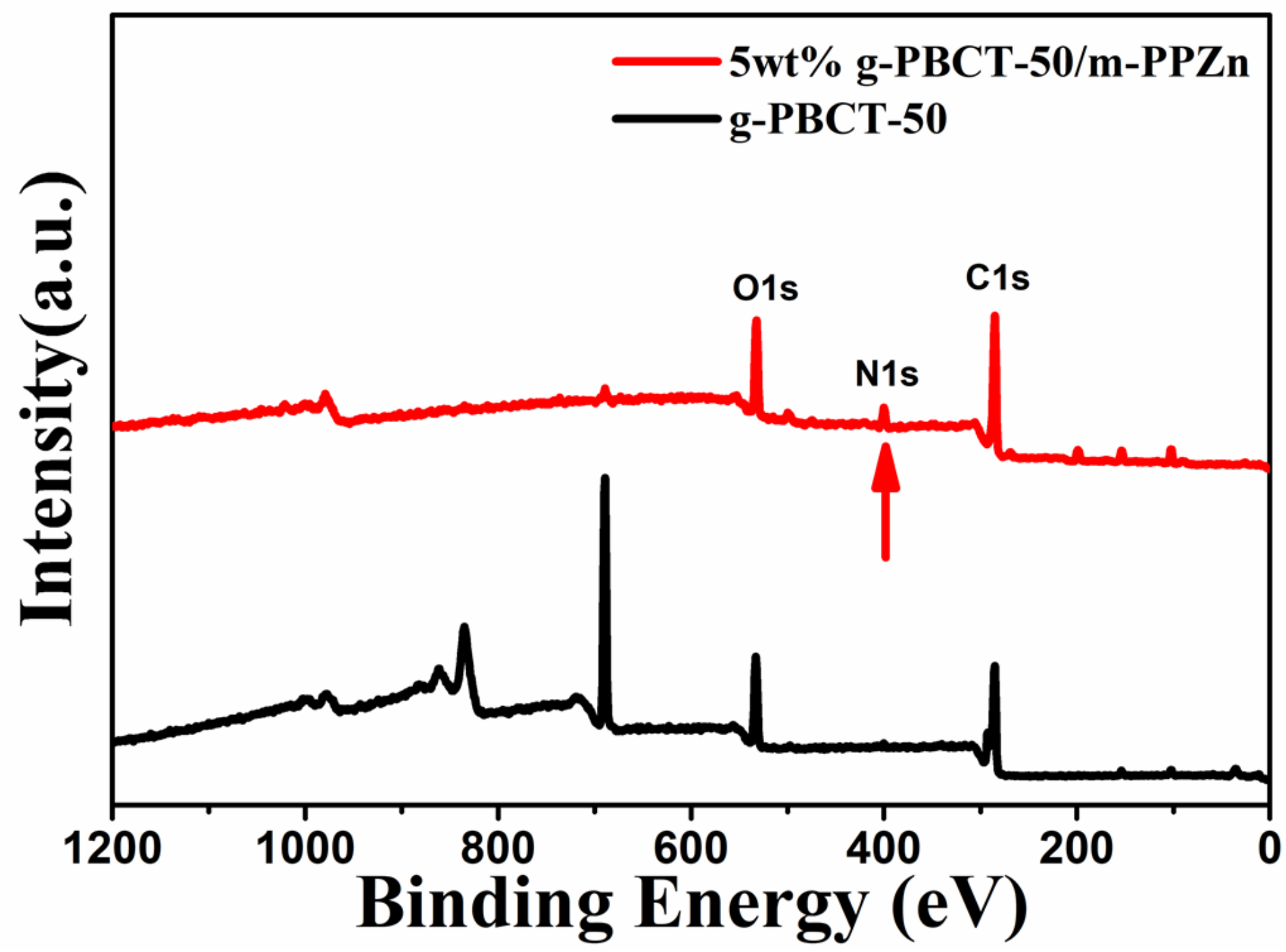

Figure 6

XPS data of the g-PBCT-50 copolyester and g-PBCT-50/m-PPZn nanocomposite. 


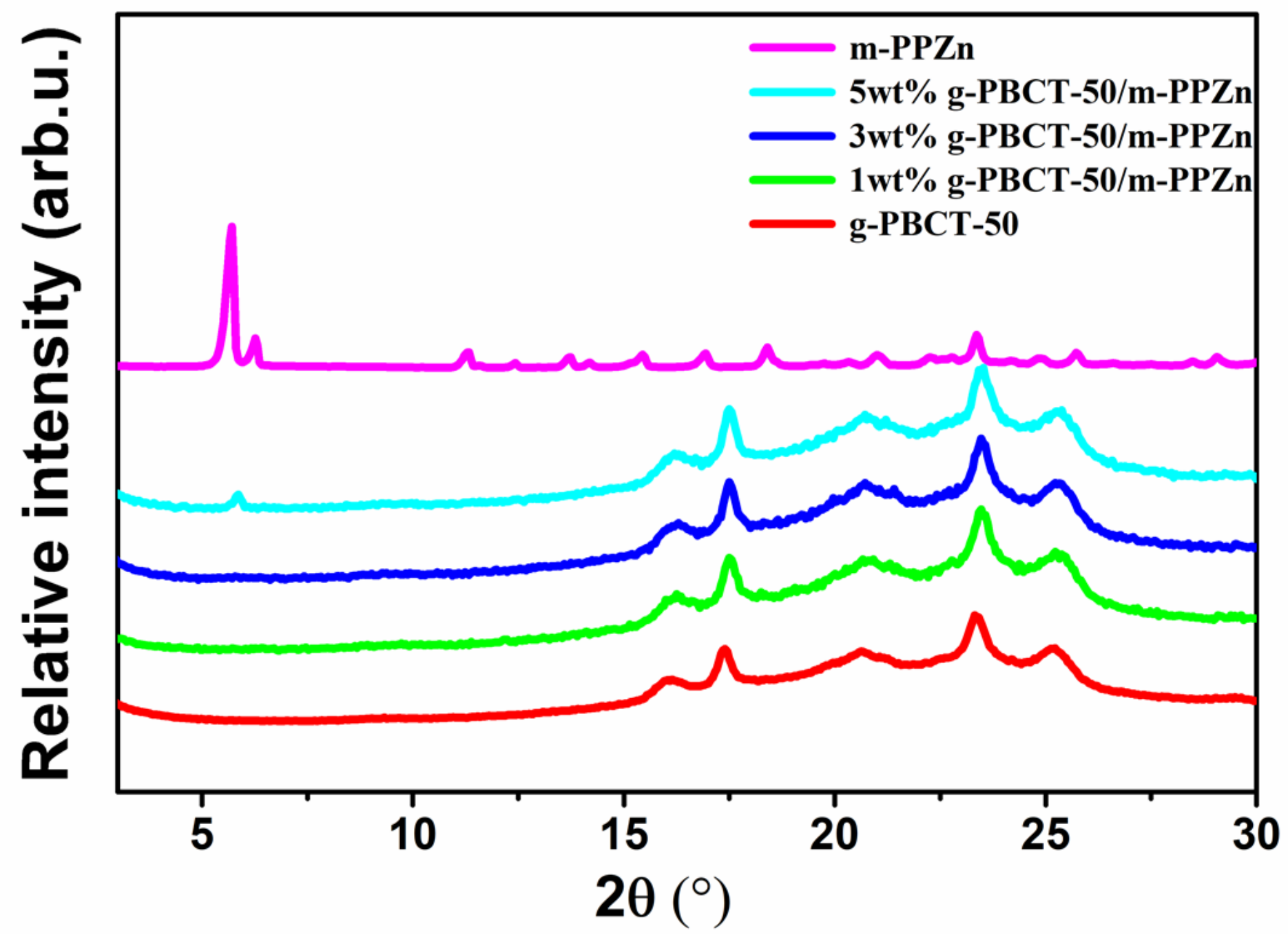

Figure 7

WAXD patterns of g-PBCT-50, m-PPZn and various weight ratio of g-PBCT-50/m-PPZn nanocomposites. 


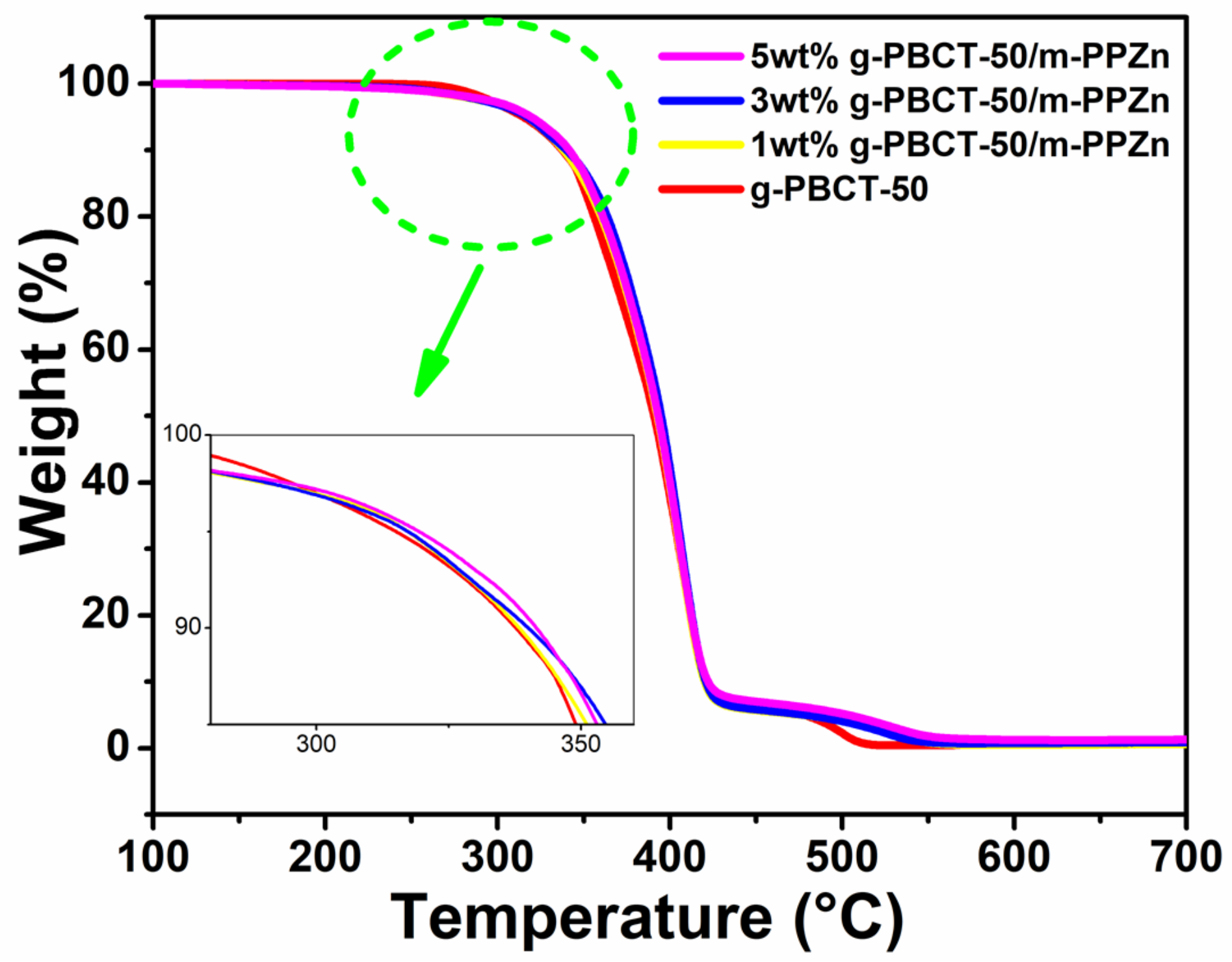

Figure 8

TGA profiles of g-PBCT-50 and various weight ratio of g-PBCT-50/m-PPZn nanocomposites. 


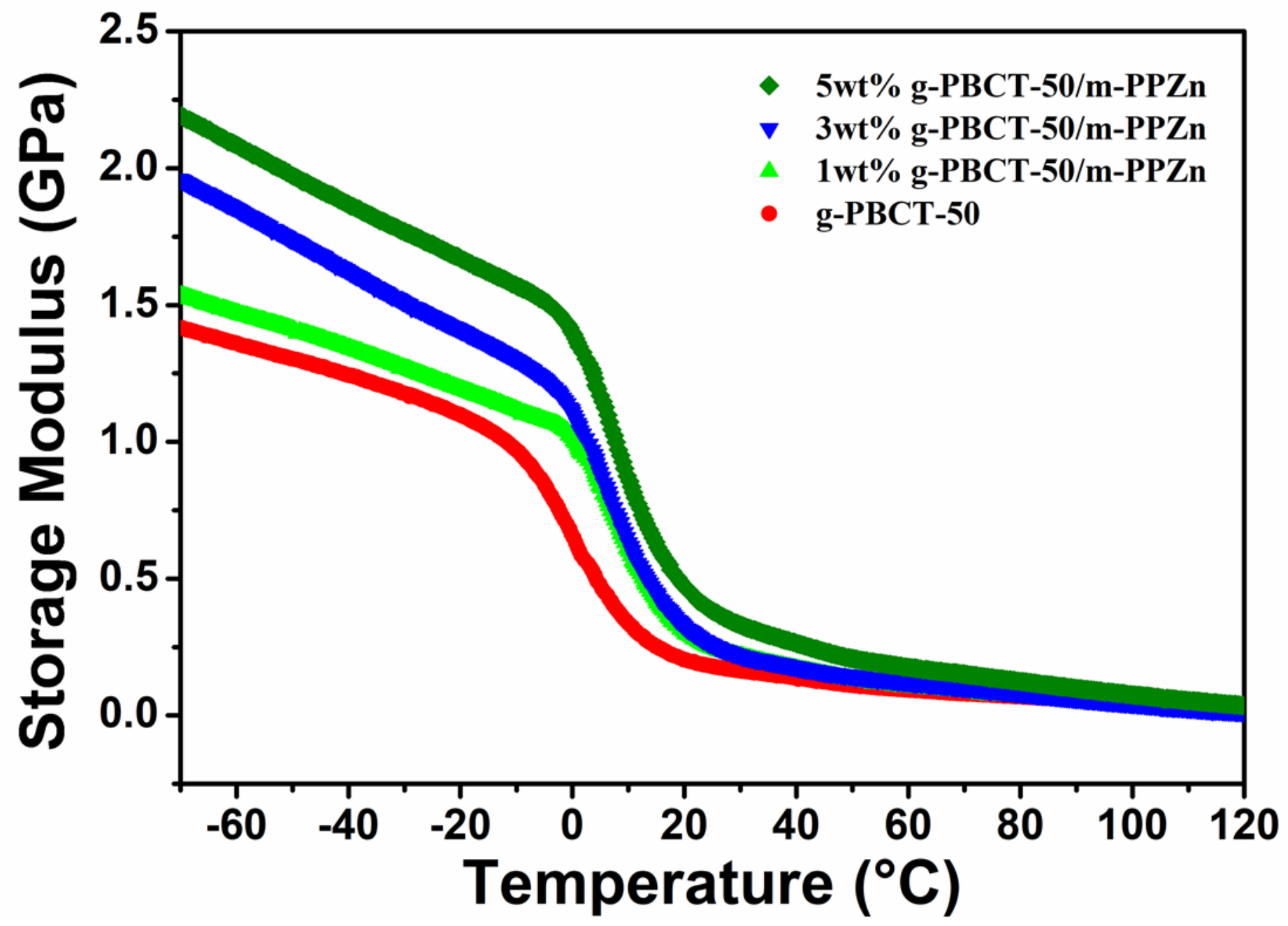

Figure 9

Dependence of the storage modulus on temperature of g-PBCT-50/m-PPZn nanocomposites. 